\title{
AMOR ENTRE AMORAS: A VIVÊNCIA LÉSBICA NOS CONTOS DE NATALIA BORGES POLESSO
}

\author{
KAROLINE ALVES LEITE (UFAM) ${ }^{1}$ \\ RITA BARBOSA DE OLIVEIRA (UFAM) ${ }^{2}$
}

\begin{abstract}
RESUMO: Neste artigo, propõe-se traçar e analisar o percurso de vivência lésbica em três contos do livro Amora (2015), de Natalia Borges Polesso, dando ênfase às fases de descoberta, aceitação e exploração da afetividade lésbica. Pretende-se refletir a respeito da representação contemporânea da homossexualidade das mulheres na literatura e da afetividade lésbica por meio das personagens dos contos "Minha prima está na cidade", "Como te extraño, Clara" e "Amora", que nomeia o livro. Atrelado a isso, discute-se sobre o modo de narrar da escritora e o seu espaço no âmbito literário. Para tanto, emprega-se como aporte teórico as discussões teóricas de Judith Butler, Michel Foucault, bem como os estudos de Tania Navarro-Swain e de Lúcia Facco.
\end{abstract}

PALAVRAS-CHAVE: Vivência lésbica. Representatividade. Modo de narrar. Natalia Borges Polesso. Amora.

ABSTRACT: In this article, we propose to outline and analyze the path of lesbian experience in three tales of the Book Amora (2015), by Natalia Borges Polesso, emphasizing the phases of discovery, acceptance and exploitation of lesbian affectivity. It intends to reflect on the contemporary representation of women's homosexuality in literature and lesbian affectivity through the characters of the tales "Minha prima está na cidade", "Como te extraño, Clara" e "Amora", which names the book. Tied to this, it discusses the way of narrating the writer and her space in the literary realm. To this end, it employs as theoretical input the theoretical discussions of Judith Butler. Michel Foucault, as well as the studies of Tania Navarro-Swain and Lúcia Facco.

KEYWORDS: Lesbian experience. Representativeness. Way of narrating. Natalia Borges Polesso. Amora.

\section{VOZES LÉSBICAS: A VISIBILIDADE EM QUESTÃO}

A escritora Natalia Borges Polesso é uma voz recente a ser destacada na produção literária brasileira contemporânea cuja obra Amora (2015), vencedora do prémio Jabuti, no ano de 2016, está contribuindo para a renovação do meio literário por meio da representação da homossexualidade das mulheres ${ }^{3}$. A vivência lésbica está sendo escrita, agora, a partir do lugar de fala de uma escritora que afirma o ativismo político presente na criação da sua obra.

A composição de Amora segue uma divisão em duas partes. A primeira é intitulada "Grandes e sumarentas" como a indicar o caráter estético dos contos cuja constituição é marcada por narrativas um pouco mais longas em contraposição à segunda parte, denominada "Pequenas e ácidas", cuja estrutura é perfeitamente em tom de reflexão filosófica-existencial, composta por textos mais curtos e profundos. Ao todo, são trinta e três textos que dão corpo à coletânea.

\footnotetext{
${ }^{1}$ Mestranda do Programa de Pós-Graduação em Letras - Estudos Literários da Universidade Federal do Amazonas (UFAM). Membro do Grupo de Estudos e Pesquisas em Literaturas de Língua Portuguesa (GEPELIP), bolsista CAPES, e-mail: aleite.kal@gmail.com.

2 Professora Doutora do curso de Letras - Língua e Literatura Portuguesa e do Programa de Pós-Graduação em Letras - Estudos Literários da Universidade Federal do Amazonas (UFAM). Líder do Grupo de Estudos e Pesquisas em Literaturas de Língua Portuguesa (GEPELIP), e-mail: ritapsocorro@gmail.com

3 Termo usado por Tania Navarro-Swain no livro O que é o Lesbianismo (2004) para se referir às relações amorosas, sexuais, afetivas entre mulheres (NAVARRO-SWAIN, 2004, p. 18-19) e que será empregado neste estudo.
} 


\section{$=$ TRAMA $=$}

Antes de adentrarmos na leitura dos contos propriamente, é viável e esclarecedor realizarmos uma breve e sucinta discussão acerca da representação da lésbica na literatura ao longo do tempo.

Houve, desde o início da história ocidental, o silenciamento da mulher que convergiu para o posterior silenciamento da homossexualidade das mulheres. Tania Navarro-Swain, em O que é o lesbianismo (2004), discorre a respeito de como a história foi construída com base na política do esquecimento na qual "reside a destruição ou o silêncio sobre a multiplicidade das relações humanas, sejam elas sociais ou sexuais" (NAVARRO-SWAIN, 2004, p. 37). Isso significa que tudo aquilo que ameaça a moral, as convicções, os costumes e as tradições e valores é destinado ao apagamento e à destruição. Logo, a existência das lésbicas desapareceu dos discursos por contrariar, desestabilizar, a hegemonia heterossexual, na medida em que o amor e o sexo entre as mulheres significa a perda de poder para o mundo patriarcal.

$\mathrm{Na}$ literatura, protagonistas lésbicas também foram alvos de invisibilidade $\mathrm{e}$ apagamento, quando não de estereótipos baseados em um modelo que segue o padrão de relacionamento aceito pela sociedade fundado a partir de oposições binárias: mulher/homem, ativo/passivo, dominante/dominado, como comprovam Santos e Inácio:

Se a representação de personagens femininas na literatura ocidental é feita de estereótipos que inferiorizam a mulher, seja devido ao contexto histórico social da obra, seja com objetivo de regular costumes, a lésbica na literatura, bem como socialmente, oscila entre as sombras da homofobia e da misoginia, ou à luz do fetiche e da hipersexualização trazida pela cultura de massa (SANTOS; INÁCIO, 2017, p. 2).

Desse modo, há uma face oculta na história e, principalmente, na literatura no que se refere à lésbica, cuja existência, quando há, é manchada pela homofobia e pela misoginia, quando não, pelo fetiche.

O cortiço, de Aluísio Azevedo, foi o primeiro romance a retratar uma cena erótica lésbica na literatura brasileira, em 1890, no qual há a descrição da relação entre Léonie e Pombinha, personagens que seguem marcadamente estereótipos femininos da prostituta e da virgem, com a atuação delas buscando a apreciação do público masculino. Posteriormente, aparece Ciranda de pedra (1954), de Lygia Fagundes Telles, que conta com a personagem Virgínia no interior de relacionamentos relações homoeróticas ${ }^{4}$ entre amigas, e isso é novamente retratado em As meninas (1973), da mesma autora, com a relação de Clotilde e Priscila. Outras obras surgem como O criador de centauros (1964), de Maria Lourdes Teixeira, Volúpia do Pecado (1948), de Cassandra Rios, bem como as escritoras Adelaide Carraro, Cíntia Moscovich, Myriam Campelo, Carol Bencimon e Milly Lacombe, apenas para delimitar algumas que criam um certo eixo do romance brasileiro no que se refere a afetividades lésbicas ${ }^{5}$ de acordo com representação e/ou autoria (POLESSO, 2018, p. 5).

Vale ressaltar que esse breve delineamento realizado tem o intuito de introduzir os próximos temas deste artigo, e não elaborar uma pesquisa aprofundada de todas as produções literárias que trataram, de forma implícita ou explícita, acerca da homossexualidade das mulheres como há nos estudos de Facco (2003), Navarro-Swain (2004) e Santos e Inácio (2017), apenas para citar alguns.

\footnotetext{
${ }^{4}$ As relações homoeróticas definem-se com base nas práticas sexuais entre mulheres, neste caso, na literatura brasileira, tal como aponta o estudo realizado por Lúcia Facco (2004, p. 64).

${ }^{5} \mathrm{O}$ termo afetividade lésbica neste artigo diz respeito ao amor, à sexualidade e à emoção das mulheres lésbicas em seus relacionamentos.
} 


\title{
$=$ TRAMA $=$
}

Nesse ponto, a proposta de estudo deste artigo consiste em traçar o percurso de vivência lésbica por meio da análise das personagens dos contos "Minha prima está na cidade", "Como te extraño, Clara" e "Amora", do livro Amora (2015), de Natalia Borges Polesso, enfatizando as fases de descoberta, aceitação e exploração da afetividade lésbica. De igual modo, pretendemos refletir sobre a representação contemporânea da homossexualidade das mulheres na literatura e da afetividade lésbica como pontos para tecermos discussões acerca de modelos de representação que foram alimentados pela produção literária de escritores e algumas escritoras, bem como pensaremos na forma como a obra de Natalia Borges Polesso traz mudanças significativas para o meio literário contemporâneo brasileiro. Por isso, trataremos aqui do modo de narrar escolhido pela escritora e de sua movimentação pelo cânone literário.

\section{A VIVÊNCIA LÉSBICA DAS AMORAS}

Nesta parte do artigo, iremos nos deter na leitura de três contos de Amora, de Natalia Borges Polesso. A tentativa é traçar e analisar o percurso de vivência lésbica a partir dos contos "Minha prima está na cidade", "Como te extraño, Clara" e "Amora". Tal percurso é permeado pelas fases de descoberta, aceitação e exploração da afetividade lésbica. A partir disso, refletiremos a respeito das relações lésbicas que se dão na vida das amoras de cada texto.

No conto "Minha prima está na cidade", conhecemos uma personagem que, embora já tenha descoberto seu desejo lésbico por outra mulher e já possua um relacionamento com uma, busca aceitar a sua sexualidade. A narrativa inicia com a personagem - cujo nome não é revelado - relatando o acontecimento de um dia em que quis fazer um jantar para algumas colegas de trabalho em seu novo apartamento. No entanto, ela não esperava que Bruna, sua namorada, voltasse cedo para casa naquele dia depois de ter se cansado de participar de um evento, o que a assusta e causa surpresa em suas colegas de trabalho. Mas toda a confusão é solucionada quando ela apresenta Bruna como sua prima que está na cidade para fazer o Enem. Aqui já nos é revelada a preocupação da personagem em esconder sua homossexualidade das pessoas do seu trabalho. Isso nos é comprovado quando ela começa a nos explicar, num tom de conversa, o porquê de ter ficado assustada quando viu Bruna e ter mentido a respeito de ela ser sua prima. Percebemos que o fato de ela nunca ter falado sobre sua namorada, tanto para as pessoas com quem trabalha como para a sua família, denota fortemente certa dificuldade em relação à aceitação de sua sexualidade. Por outro lado, isso não é visto como problema para Bruna, como nos conta a personagem narradora:

\begin{abstract}
Aproveitei que a Bruna estava viajando e decidi convidar o pessoal da firma. É que eu nunca tinha falado da Bruna para nenhuma das minhas colegas. Eu trabalho num lugar que não me permite fazer isso. Sei lá, a Bruna é designer, acho que, no meio em que ela circula, é mais fácil aceitar. Eu vou jantar com os amigos da Bruna, amigos do trabalho. Eles sabem que a gente é um casal, porque a Bruna não tem problemas com isso. Eu tenho. Quer dizer, já tive mais, mas agora consigo lidar até bem com essa questão de sexualidade, claro, dentro da minha cabeça. Não conto para muitas pessoas, tem gente que não precisa saber, nem a minha família (POLESSO, 2015, p. 74-75).
\end{abstract}

Por trás dessa atitude da personagem há uma série de questões que podem ser levantadas, principalmente, as inerentes ao modo como a sociedade se configura e à forma como as relações lésbicas foram e ainda são vistas. Podemos começar com o que nos fala Michel Foucault, em História da sexualidade I (1988), sobre a relação entre sexo e poder que se constitui como um modo de repressão. Isto é, o poder regula a sexualidade humana a partir de discursos de interdição e reprime práticas sexuais que são consideradas irregulares, na medida em que a conduta sexual normativa baseia-se na concepção binária de sexualidade. 


\section{$=$ TRAMA $=$}

Portanto, a sexualidade é um dos instrumentos mais eficazes utilizados nas articulações de controle social: "Nas relações de poder, a sexualidade não é o elemento mais rígido, mas um dos dotados da maior instrumentalidade: utilizável no maior número de manobras, e podendo servir de ponto de apoio, de articulação às mais variadas estratégias." (FOUCAULT, 1988, p. 114). Com base nisso, assumir a homossexualidade das mulheres é transgredir essa forma de repressão e buscar se posicionar perante uma sociedade que aceita e impõe apenas a heteronormatividade como sexualidade possível para homens e mulheres.

A heteronormatividade é entendida como a regulação das relações sexuais imposta pelos mecanismos de poder, conforme esclarece Foucault (1988, p. 32): "um discurso onde a conduta sexual da população é tomada, ao mesmo tempo, como objeto de análise e alvo de intervenção". Neste sentido, para o poder, a prática sexual que transgrida a norma deve ser eliminada ou silenciada. De fato, a homossexualidade, ao desestabilizar aquela norma, questiona o poder e representa uma ameaça às instituições que o respaldam a partir da transformação das relações de gênero.

Neste ponto, a heteronormatividade exclui as relações lésbicas, pois não as entende como práticas sexuais legítimas na medida em que a concepção de sexo, durante muito tempo, esteve baseada no falo, sendo, por isso, a verdadeira sexualidade a masculina em oposição à mulher assexuada - forma de discurso para exercer o poder sobre a sexualidade das mulheres disseminada durante muitos anos -, como destaca Lúcia Facco (2003, p. 70). Atrelado a isso está, evidentemente, o silenciamento do desejo lésbico, como afirma Facco: "O desejo feminino e, por consequência lógica, o desejo lésbico vêm sendo silenciados por tanto tempo devido, exatamente, à preocupação em se manter o sistema de dominação das sociedades falocráticas, em que há sempre uma sujeição das mulheres ao discurso ditado pelos homens" (2003, p. 71).

No discurso das sociedades falocráticas, o sexo visa sobretudo à reprodução. Assim, o desejo de uma mulher por outra seria novamente invalidado, uma vez que não há possibilidade de reprodução. Tais discursos permanecem no imaginário social de muitas pessoas e colaboram para o preconceito e a discriminação. Diante do exposto, podemos pensar que o motivo tido como impedimento para a personagem não aceitar a sua homossexualidade é perpassado, justamente, pelos discursos de controle da sexualidade que contribuem, veementemente, para a visão preconceituosa acerca da homossexualidade das mulheres.

A narração empreendida pela personagem do cotidiano e da relação de convivência estabelecida entre ela e Bruna mostra que não há distinção entre um relacionamento heterossexual e um homossexual, uma vez que em ambos há diferentes formas de convivência entre os casais no que diz respeito às suas particularidades, mas que a forma de se relacionar é semelhante quanto à cumplicidade, ao afeto, à estima, aos desentendimentos, às mágoas, aos conflitos e ao bem estar.

Por outro lado, o impasse da aceitação mostrado pela personagem que narra o conto deixa evidenciar que ainda paira pelos relacionamentos lésbicos a sombra do preconceito, da discriminação e da lesbofobia. No entanto, estas sombras se dissolvem quando há aceitação de si mesma, pois a liberdade de viver o que se quer não pode ser reprimida perante os julgamentos alheios, como Bruna nos permite observar ao dizer que "a verdade teria sido indolor" se houvesse aceitação por parte de sua namorada, que, em seguida, reitera: "O fato é que continuamos tentando" (POLESSO, 2015, p. 79).

De outro modo, em "Como te extraño, Clara", Fernanda, professora, ama Clara, aluna, mas há um impedimento para que as duas possam ter uma vida juntas: Fernanda é casada com Eduardo. Além disso, Fernanda tem medo de sair da sua zona de conforto construída com base no casamento com Eduardo e na criação do filho, Rafael. Por isso, seu relacionamento com 


\section{$=$ TRAMA $=$}

Clara é escondido de todas as formas, embora Clara deseje que Fernanda deixe o marido e viva apenas com ela.

Somente após ter sofrido um grave acidente de trânsito, Fernanda vê sua vida ser afetada por uma mudança abrupta, e isso se refletirá na vida de Clara. Eduardo descobre o relacionamento das duas e sai de casa. É assim que Fernanda percebe que tudo o que é novo causa medo, estranhamento:

Fernanda pensa no que faria sem Eduardo, no que faria com Rafael. Pensa onde todas as coisas organizadas de sua vida iriam parar, caso tivesse um novo caminho. Logo depois, pensa que talvez esteja se precipitando, não sabe direito o que acontece, se Clara quer realmente fazer aquilo que diz. Pensa se ela mesma quer assumir outro papel naquela peça ridícula que vive até ali. E diz em voz baixa como te extraño, Clara. Porque tudo está mesmo estranho e escuro naquela talvez possibilidade tão pequena de mudar de vida, tão farelenta, como seus ossos depois da batida. Não sabe muito bem como funcionariam as coisas, todas essas coisas novas, perigosas e atraentes que se apresentavam a ela (POLESSO, 2015, p. 128).

O estranhamento é uma sensação recorrente nas personagens dos contos diante de sua homossexualidade, como pontuou Paloma Vidal no prefácio do livro Amora:

A estranheza ao lado da escuridão, e também da mudança, de algo que se abre, uma possibilidade, pequena e persistente, que quando menos esperamos se torna real, com uma naturalidade que primeiro surpreende e depois não mais, alegrando-nos como um beijo que vira sorriso dentro da boca (POLESSO, 2015, p. 1).

Por isso, há uma quinta-feira estranha, cujo tempo tempestuoso espelha esta estranheza, que precede a mudança de rumo da vida de Fernanda e Clara, anunciando uma possibilidade de liberdade para viverem o seu relacionamento, como anuncia Fernanda: "Agora, é isso. Nós duas. Eu, parte quebrada, tu com essa cara de susto... E o guri” (POLESSO, 2015, p. 129). Ao que Clara reage com emoção e intensidade. Depois disso, haverá apenas Fernanda, Clara e Rafael em um novo caminho.

Da mesma forma, é o estranho e bonito gesto de estarem de mãos dadas que despertará em Amora o seu desejo e amor por Angélica durante uma partida de torneio de xadrez. As duas garotas se apaixonam uma pela outra antes mesmo de notarem suas emoções e seus sentimentos. A beleza do conto "Amora" se revela profundamente na forma como o amor de Amora por Angélica acontece de forma tranquila e é aceito com naturalidade por ambas. Ora, não é de outra forma que devem ser considerados os diferentes amores existentes entre homens e mulheres, com naturalidade. Em outras palavras, o amor entre ambas é legítimo. É sublime o gesto de amor uma pela outra na medida em que ser e saber-se amada é a maior medalha de Amora:

Amora segurava a mão imaginária de Angélica, enquanto na hora do recreio deitavam sob uma jabuticabeira. Ambas sentiam todas aquelas coisas que não teriam nomes, todos aqueles movimentos dentro. Até que Angélica disse: Amora, eu te amo. Amora continuou olhando para frente, onde umas crianças brincavam no parquinho do pátio. Deitou a cabeça no ombro de Angélica, que Ihe deu um beijo na têmpora, um beijo comprido, cheio de pensamentos quentes. Mas foi a coisa mais brega, dita depois, que fez Amora entender: Você é quase toda amor (POLESSO, 2015, p. 156).

Pelo que o conto nos permite inferir, Amora está na adolescência. Este é um fator muito importante para notarmos que a narrativa do conto acontece baseada no ritmo das emoções e 


\section{$=$ TRAMA $=$}

dos sentimentos que a personagem Amora nutre pela personagem Angélica, isto é, de modo frenético, denotando a euforia e o anseio que a atravessam.

Nos três contos analisados, constatamos que as personagens, todas amoras, vivem seus amores em diferentes estágios da vida, algumas são adultas, outras são mais jovens, mas há intensidade no que sentem e liberdade, em alguns casos, para isso.

Embora o percurso de vivência lésbica não seja o mesmo para cada personagem, o que se destaca é a exploração da afetividade lésbica que acontece de uma forma ou de outra, ainda que haja algum impedimento para tal. O relevante em cada narrativa é a liberdade com que os relacionamentos lésbicos se realizam, evidenciando que não há nada para ser escondido ou silenciado na homossexualidade das mulheres, e sim reconhecer as relações lésbicas como fruto do amor legítimo das amoras.

A relação lésbica estabelecida por essas personagens foge à relação heterossexual tida como modelo na sociedade patriarcal. Nesse sentido, são mulheres lésbicas que derrubam estereótipos baseados na noção de gênero construída socialmente em diferentes contextos históricos e indissociável "das interseções políticas e culturais em que invariavelmente ela é produzida e mantida", como salienta Judith Butler (2003, p. 20), na obra Problemas de gênero. Afinal, a identidade de gênero provém de uma série de atos performativos repetidos pelo indivíduo por meio de gestos corporais, falas, movimentos e papéis sociais a fim de materializar a diferença sexual para impor a heterossexualidade. Nessa medida, as personagens lésbicas de Amora não perpetuam os estereótipos que buscam regular qualquer relacionamento tendo por base o binarismo homem/mulher tido como ordem sexuada do mundo.

\section{REPRESENTATIVIDADE, MODO DE NARRAR E LUGAR DE FALA}

A literatura viabiliza o conhecimento de si e do outro. Na leitura dos contos de Amora, há uma pluralidade de vozes femininas que falam por si e por suas iguais na medida em que a liberdade de cada uma é uma constante a ser perseguida e conquistada diariamente. As amoras de Natalia Borges Polesso afirmam seus conflitos, desejos, suas tristezas, seus amores e suas identidades, e, sobretudo, buscam afirmar sua humanidade, pois não são outros os temas que permeiam os contos de Amora senão temas da vida do ser humano, do seu dia a dia, dos seus amores.

Pensar o modo de narrar de Natalia Borges Polesso é compreender que o matiz fecundo dos contos de Amora é o da vivência lésbica. Dado isso, o cunho político de sua escrita reverbera por cada um deles de modo a se configurar numa canção para afirmar a existência de personagens lésbicas enquanto seres que vivem de modo honesto e, acima de tudo, constituem a sociedade, agem e contribuem com o mundo, e, por isso, merecem ser reconhecidas.

A proposta estética de Polesso é a de uma prosa fluida, com palavras muito bem empregadas e prontas para tocar o leitor, com metáforas que circulam discretamente pelo texto, contribuindo significativamente para a narrativa. Amora preenche uma lacuna no campo literário no que diz respeito à autoria e à representação da homossexualidade das mulheres na literatura, que, outrora, foi composta por silenciamentos e apagamentos. Por esse motivo, gira em torno de uma escolha política reafirmada pela própria vivência da autora enquanto sujeito e, outra vez mais, por sua produção literária, como escreve Polesso:

Amora foi idealizado no interior de uma escolha que é política, porque se faz fundamental para mim como autora e leitora e que cumpre a função de expor representações mais plurais. A escolha também se faz estética, pela mesma motivação: revisitar estereótipos para repensar o estar-no-mundo dessas personagens. (POLESSO, 2018, p. 5). 


\section{$=$ TRAMA $=$}

A partir desse posicionamento, Natalia Borges Polesso salienta que sua obra foi pensada a partir de personagens lésbicas. Ou seja, nela, há um tom de representatividade fortemente baseado na importância de promover a visibilidade de vivências lésbicas na literatura, levantando a bandeira de um grupo não homogêneo e ao qual the é negada a existência em prol de um padrão de vida heteronormativo estabelecido e defendido pela sociedade. Ao mesmo tempo, tais personagens lésbicas se constituem como sujeitos que vivenciam experiências que permeiam a existência de qualquer sujeito, sem distinção de sexualidade:

O jogo da autora é não propor identificações simples: não é apenas uma literatura para lésbicas. É uma literatura sobre sujeitos lésbicos que existem em uma sociedade que valoriza e protege apenas a heterossexualidade, Natalia, como escritora lésbica assumida, não se propõe a pensar o seu "si mesmo" como uma reflexão existencial. Não há nada errado ou qualquer insatisfação dela com a própria sexualidade, ao contrário, ela se posiciona como sujeito a partir desse lugar. O que ela sim, pretende, é narrar um si mesmo que o tempo todo está colocado pela sociedade patriarcal na posição inferior em relação a um outro (BRITTO, 2018, p. 107).

É, por isso, que os contos de Amora tanto tematicamente como esteticamente pedem o posicionamento e o envolvimento do leitor na medida em que sua existência é posta em relação profunda com a de personagens que vivem seus amores proibidos e contestados pela sociedade.

O ponto central de diferenciação da escrita de Natalia Borges Polesso para a escrita de livros como O poço da solidão (1928), de Radclyffe Hall, consiste no modo de narrar suas personagens lésbicas. Embora o livro de Hall tenha sido considerado a Bíblia do lesbianismo e tenha proporcionado visibilidade para relações sexuais entre mulheres, ainda que tenha sido julgado e condenado (FACCO, 2003, p. 56-58), descreve um final trágico em que Stephen precisa abdicar de Mary para que ela tenha uma vida normal se casando com um homem. Ao passo que na coletânea de Polesso, não cabe aqui o fim trágico da lésbica que era obrigada a pagar por manter relações sexuais com mulheres. O que há, de fato, é a narração da vida das amoras e de seus amores, sem a intromissão de destinos cruéis e estigmatizados considerados, durante muito tempo, como modelos de escrita, já que a maior parte da literatura era produzida por homens, o que fundamenta os estereótipos acerca das personagens lésbicas e de seus relacionamentos, posto que, em sua visão machista e heteronormativa, esses escritores não concebiam como real o amor entre duas mulheres para além do destino repulsivo de servir ao masculino, partindo disso, claramente, a negação da legitimidade da sexualidade lésbica.

Contrapondo esse cenário, as personagens lésbicas de Natalia Borges Polesso trazem a possibilidade de reconhecimento para muitas leitoras lésbicas e leitores em geral que irão conhecer o universo narrativo de suas personagens, enquanto este permite a visão de uma vida em que as lésbicas são livres para viver o amor e se sentirem felizes por vislumbrarem um futuro no qual o relacionamento entre duas mulheres pode ter um final feliz, como no romance Carol (1953), de Patricia Highsmith, primeiro livro nos Estados Unidos a retratar personagens lésbicas que tiveram um final feliz, na medida em que houve a possibilidade de elas construírem uma vida juntas.

Isso nos leva a pensar sobre a questão do espaço na literatura cujo debate é recente, visto que, de acordo com Regina Dalcastagnè, "os estudos literários (e o próprio fazer literário) se preocupam com os problemas ligados ao acesso à voz e à representação dos múltiplos grupos sociais" (DALCASTAGNÈ, 2012, p. 17, grifos da autora), cujo o cerne é o lugar de fala, 


\section{$=$ TRAMA $=$}

ou seja, quem fala e em nome de quem. No interior dessas discussões, o termo chave é representação, reconhecido por suas ressonâncias políticas e sociais.

Sendo assim, durante muito tempo, quem escreveu sobre a mulher e a lésbica na literatura foram os homens, com seu discurso marcadamente misógino e machista. No entanto, no panorama atual, e nisso reside a importância das obras de escritoras como Natalia Borges Polesso e Angélica Freitas, o silêncio que afugenta a literatura lesbiana ${ }^{6}$ é quebrado pela produção de escritoras que possuem legitimidade e autoridade para falar sobre o assunto, como corrobora Dalcastagnè (2012, p. 17): "O silêncio dos marginalizados é coberto por vozes que se sobrepõem a eles, vozes que buscam falar em nome deles, mas também, por vezes, é quebrado pela produção literária de seus próprios integrantes.". Atrelado a isso, como dito anteriormente, está o conceito chave de representação no sentido de falar em nome do outro. Ora, no campo literário, Natalia Borges Polesso afirma sua escrita como representativa da homossexualidade das mulheres na literatura, uma vez que "mulheres e homens [...], negros e brancos [...], homossexuais e heterossexuais vão expressar o mundo de diferentes maneiras" (DALCASTAGNÈ, 2012, p. 20). Nesse sentido, devemos ressaltar a profundidade e a relevância política e social de Amora para o contexto literário e social brasileiro atual em que se discute amplamente a diversidade de orientações sexuais existentes, dando voz e visibilidade a um grupo que foi, por vezes, mal representado e/ou apagado do cânone literário.

\section{PALAVRAS SOBRE RESISTÊNCIA}

Amora comprova que o fazer literário é também um ato político na medida em que dá voz ao outro, ao ser excluído da sociedade. Natalia Borges Polesso insere no campo literário a representação da homossexualidade das mulheres de forma legítima, uma vez que também é escritora e lésbica, retratando as relações lésbicas livres de estereótipos e de modelos baseados na norma heterossexual.

As personagens lésbicas dos três contos lidos, como vimos, percorrem determinadas fases dentro de si mesmas e na vida antes e/ou no decorrer de relacionamentos lésbicos. Atravessam-nas o estranhamento causado pela descoberta de um desejo pelo mesmo sexo que é, também, uma certa estranheza de si mesmas, mas que é dissipada quando a afetividade lésbica se realiza, já que, como afirma a personagem do conto "Minha prima está na cidade", "é também pelas estranhezas que as pessoas se unem" (POLESSO, 2015, p. 76).

A homossexualidade das mulheres resiste por meio dos contos de Amora. Resistir é existir, por isso faço minhas as palavras de Lúcia Facco, pois no momento o que se busca, verdadeiramente, é "deixar bem claro um modelo de identificação, busca-se dar voz ao que antes era dito somente por um silêncio imposto. Buscam-se a visibilidade, a obviedade. As lésbicas não querem mais sussurros, elas querem mesmo é gritar" (FACCO, 2003, p. 89). Gritar sua existência, como as personagens lésbicas de Natalia Borges Polesso gritam quando seguem em frente, exploram a si mesmas, enfrentam a sociedade e vivem com legitimidade sua homossexualidade.

Ademais, a leitura dos contos de Amora realizada neste artigo, a partir do percurso de vivência lésbica pautado nas fases de descoberta, aceitação e vivência da afetividade lésbica, não teve o intuito de ser redutora nem de limitar a vivência das personagens lésbicas para que se coadunassem às fases propostas, mas buscou traçar um norte para a realização da análise das narrativas.

\footnotetext{
${ }^{6}$ Esse termo é usado por Natalia Borges Polesso no artigo Geografias lésbicas: literatura e gênero. Revista Criação \& Crítica, n. 20, 2018, p. 3-19. Disponível em:<https://doi.org/10.11606/issn.1984-1124.v0i20p3-19> Acesso em: 5 jan. 2019.
} 


\section{$=\mathrm{T} R A M A=$}

\section{REFERÊNCIAS}

BUTLER, Judith. Problemas de gênero: feminismo e subversão da identidade. Trad. Renato Aguiar. Rio de Janeiro: Civilização Brasileira, 2003.

BRITTO, Milena. Escritas e escritoras: modos de narrar a si mesmo no séc. XXI. Revista Estudos Linguísticos e Literários, nº 59, Jan.-Jun., Salvador, 2018, pp. 100-108. Disponível em:

<https://portalseer.ufba.br/index.php/estudos/article/viewFile/28860/17069> Acesso em: 26 dez. 2018.

DALCASTAGNĖ, Regina. Literatura brasileira contemporânea: um território contestado. Vinhedo, Editora Horizonte. Rio de Janeiro: Editora da Uerj, 2012.

FACCO, Lúcia. As heroínas saem do armário: literatura lésbica contemporânea. São Paulo: Edições GLS, 2003.

FOUCAULT, Michel. História da sexualidade I: A vontade de saber. Trad. Maria Thereza da Costa

Albuquerque e J.A. Guilhon Albuquerque. Rio de Janeiro: Edições Graal, 1988.

NAVARRO-SWAIN, Tânia. O que é lesbianismo. São Paulo: Brasiliense, 2004.

POLESSO, Natalia Borges. Amora. Porto Alegre: Não Editora, 2015.

Geografias lésbicas: literatura e gênero. Revista Criação \& Crítica, n. 20, 2018, p. 3-19. Disponível em:<https://doi.org/10.11606/issn.1984-1124.v0i20p3-19> Acesso em: 5 jan. 2019.

SANTOS, Claudiana Gois dos; INÁCIO, Emerson da Cruz. A bruta flor do querer: amor, performance e heteronormatividade na afetividade lésbica. Seminário Internacional Fazendo Gênero 11 \& 13th Women's Worlds Congress (Anais Eletrônicos), Florianópolis, 2017. Disponível em:

<http://www.en.wwc2017.eventos.dype.com.br/resources/anais/1498785683_ARQUIVO_ABrutaFlordoQuere rClaudianaGois13MundodeMulheres.pdf> Acesso em: 2 dez. 2018. 